\title{
Long-Term Combination Treatment of Azithromycin with Other Macrolides: A New Era
}

\author{
Jiro Fujita and Haley L. Cash \\ Key words: diffuse panbronchiolitis, bronchiectasis, long-term treatment, erythromycin, clarithromycin, \\ azithromycin
}

(Intern Med 51: 1289-1291, 2012)

(DOI: 10.2169/internalmedicine.51.7339)

Diffuse panbronchiolitis (DPB) is a chronic inflammatory disease of the airways. Before the discovery of low-dose erythromycin (EM) therapy in 1985, patients with DPB suffered from high rates of mortality despite treatment with a combination of various antibiotics and the use of supportive therapy such as oxygen administration (1). Low-dose erythromycin therapy (400 to $600 \mathrm{mg} / \mathrm{day}$ ) was found to not only improve the survival of patients with DPB (2) through potential antimicrobial effects, but also it was suggested to possess anti-inflammatory properties (1). More recently, Kadota et al. have demonstrated that 6-month treatment with clarithromycin (CAM) is also safe and effective at improving clinical conditions of patients with DPB, while also providing anti-inflammatory effects (3). Most recently, the previously mentioned 14-membered macrolides (EM and CAM), as well as 15 -membered macrolide, azithromycin (AZM) were found to elicit immunomodulatory effects that are not demonstrated by 16 -membered macrolides (4). Since AZM has been used as a three-day regimen or one-day (extended-release formula) in Japan, it is rarely used as a long-term treatment for respiratory infections.

In this issue, Yamamoto et al. report a case of refractory chronic respiratory tract infection due to Pseudomonas aeruginosa that was successfully controlled by combination therapy using CAM (400 mg once daily) and AZM (250 mg once daily) treatment for 2 years (5). In 2011, two review articles concerning long-term treatment of AZM were published regarding patients with cystic fibrosis $(C F)(6,7)$. It has been demonstrated that long-term use of AZM can improve lung function, especially for Pseudomonas aeruginosa-colonized CF patients with no evidence of increased adverse events with AZM use (6-14). In addition, Li et al. have recently reported that long-term treatment of AZM is effective for controlling DPB in Chinese patients (Table 1) (15). Furthermore, it has also been reported that long-term treatment of AZM is effective for preventing exacerbation of chronic obstructive pulmonary diseases (COPD) (Table 1) (16-18).

Yamamoto et al. examined the differences in the effects of CAM and AZM, and discovered that AZM and CAM exerted different immunomodulatory effects in murine dendritic cells $(5,19)$. AZM increased interleukin (IL)-10 production and inhibited the excess immune response, whereas CAM inhibited IL-2 and IL-6 production. Although both drugs (AZM and CAM) affected immune responses, they exhibited different immune alterations. It was suggested that these differences in immunomodulatory effects explain the improved efficacy of the combination therapy of CAM and AZM in comparison to treatment with one drug alone (5).

Although the clinical efficacy of long-term treatment of azithromycin has been well established overseas, clinical application in Japan is lacking. Therefore, long-term treatment of azithromycin or long-term combination treatment of azithromycin with other macrolides should be considered if other macrolides are not effective. Additionally, the efficacy of macrolide combination therapy should be further examined in clinical studies as well as in laboratory studies.

Author's disclosure of potential Conflicts of Interest (COI). Jiro Fujita: Speaking fees, Shionogi, Astellas Pharma, Taisho Toyama Pharmaceutical, Dainippon Sumitomo Pharma, Pfizer Japan and Daiichi Sankyo. 
Intern Med 51: 1289-1291, 2012 DOI: 10.2169/internalmedicine.51.7339

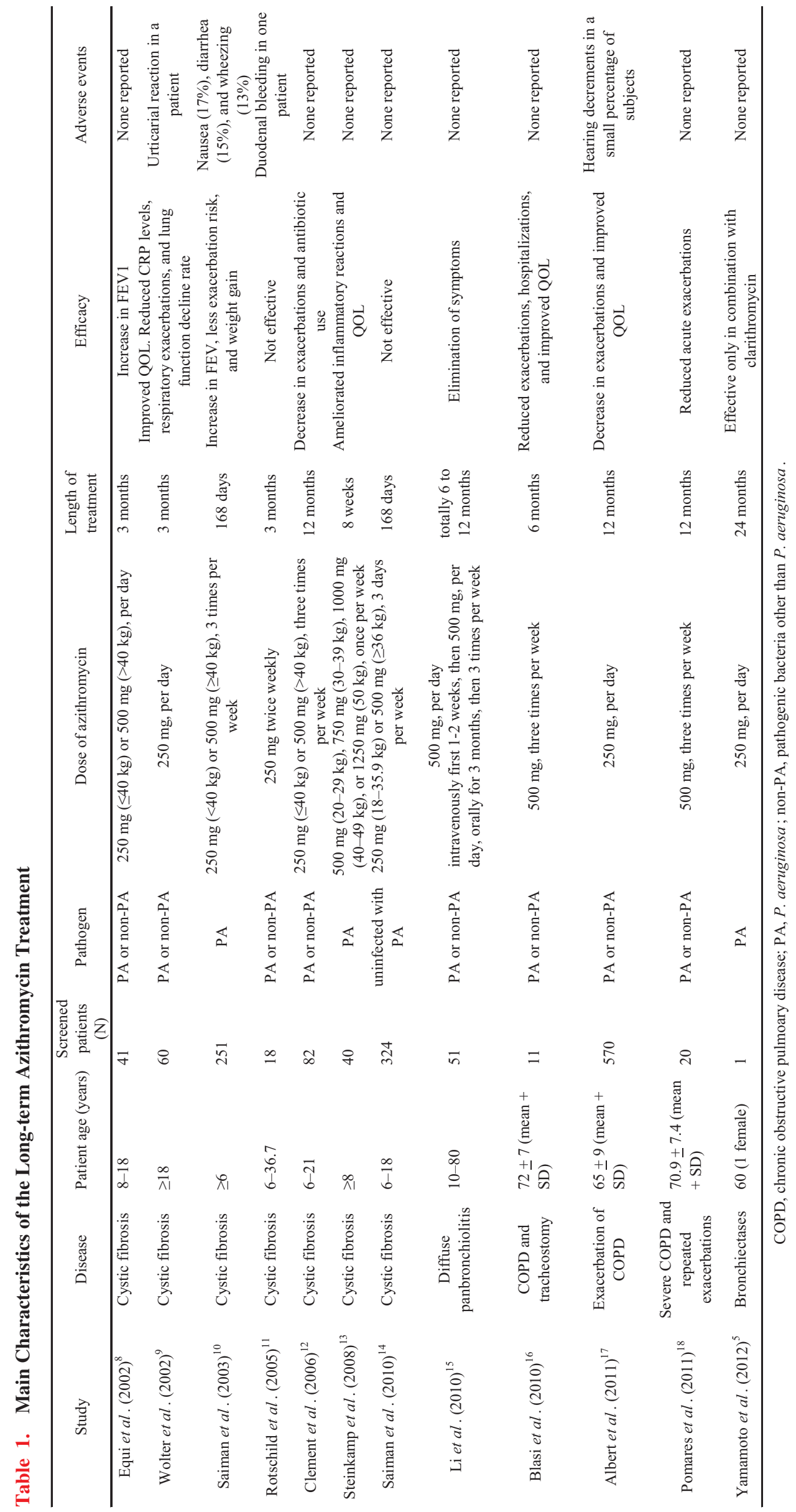




\section{References}

1. Kudoh S, Azuma A, Yamamoto M, Izumi T, Ando M. Improvement of survival in patients with diffuse panbronchiolitis treated with low-dose erythromycin. Am J Respir Crit Care Med 157: 1829-1832, 1998.

2. Kudoh $S$, Uetake T, Hagiwara $K$, et al. Clinical effects of lowdose long-term erythromycin chemotherapy on diffuse panbronchiolitis. Nihon Kyobu Shikkan Gakkai Zasshi 25: 632-642, 1987.

3. Kadota J, Mukae H, Ishii H, et al. Long-term efficacy and safety of clarithromycin treatment in patients with diffuse panbronchiolitis. Respir Med 97: 844-850, 2003.

4. Takizawa H, Desaki M, Ohtoshi T, et al. Erythromycin modulates IL-8 expression in normal and inflamed human bronchial epithelial cells. Am J Respir Crit Care Med 156: 266-271, 1997.

5. Yamamoto Y, Izumikawa K, Hosogaya N, et al. A case of refractory chronic respiratory tract infection due to Pseudomonas aeruginosa successfully controlled by combination of clarithromycin and azithromycin. Intern Med 51: 1383-1386, 2012.

6. Southern KW, Barker PM, Solis-Moya A, Patel L. Macrolide antibiotics for cystic fibrosis. Cochrane Database Syst Rev 12: CD 002203, 2011.

7. Cai Y, Chai D, Wang R, Bai N, Liang BB, Liu Y. Effectiveness and safety of macrolides in cystic fibrosis patients: a meta-analysis and systematic review. J Antimicrob Chemother 66: 968-978, 2011.

8. Equi A, Balfour-Lynn IM, Bush A, Rosenthal M. Long term azithromycin in children with cystic fibrosis: a randomised, placebo-controlled crossovertrial. Lancet 360: 978-984, 2002.

9. Wolter J, Seeney S, Bell S, Bowler S, Masel P, McCormack J. Effect of long term treatment with azithromycin on disease parameters in cystic fibrosis: a randomized trial. Thorax 57: 212-216, 2002.

10. Saiman L, Marshall BC, Mayer-Hamblett N, et al; Macrolide Study Group. Azithromycin in patients with cystic fibrosis chroni- cally infected with Pseudomonas aeruginosa: a randomized controlled trial. JAMA 290: 1749-1756, 2003.

11. Rotschild M, Elias N, Berkowitz D, et al. Autoantibodies against bactericidal/permeability-increasing protein (BPI-ANCA) in cystic fibrosis patients treated with azithromycin. Clin Exp Med 5: 8085,2005

12. Clement A, Tamalet A, Leroux E, Ravilly S, Fauroux B, Jais JP. Long term effects of azithromycin in patients with cystic fibrosis: A double blind, placebo controlled trial. Thorax 61: 895-902, 2006.

13. Steinkamp G, Schmitt-Grohe S, Döring G, et al. Once-weekly azithromycin in cystic fibrosis with chronic Pseudomonas aeruginosa infection. Respir Med 102: 1643-1653, 2008.

14. Saiman L, Anstead M, Mayer-Hamblett N, et al. AZ0004 Azithromycin Study Group. Effect of azithromycin on pulmonary function in patients with cystic fibrosis uninfected with Pseudomonas aeruginosa: a randomized controlled trial. JAMA 303: 1707-1715, 2010.

15. Li H, Zhou Y, Fan F, et al. Effect of azithromycin on patients with diffuse panbronchiolitis: retrospective study of 51 cases. Intern Med 50: 1663-1669, 2011.

16. Blasi F, Bonardi D, Aliberti S, et al. Long-term azithromycin use in patients with chronic obstructive pulmonary disease and tracheostomy. Pulm Pharmacol Ther 23: 200-207, 2010.

17. Albert RK, Connett J, Bailey WC, et al. COPD Clinical Research Network. Azithromycin for prevention of exacerbations of COPD. N Engl J Med 365: 689-698, 2011.

18. Pomares X, Montón C, Espasa M, Casabon J, Monsó E, Gallego M. Long-term azithromycin therapy in patients with severe COPD and repeated exacerbations. Int $\mathrm{J}$ Chron Obstruct Pulmon Dis 6: 449-456, 2011.

19. Sugiyama K, Shirai R, Mukae H, et al. Differing effects of clarithromycin and azithromycin on cytokine production by murine dendritic cells. Clin Exp Immunol 147: 540-546, 2007.

(C) 2012 The Japanese Society of Internal Medicine http://www.naika.or.jp/imindex.html 